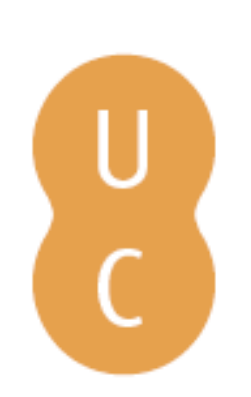

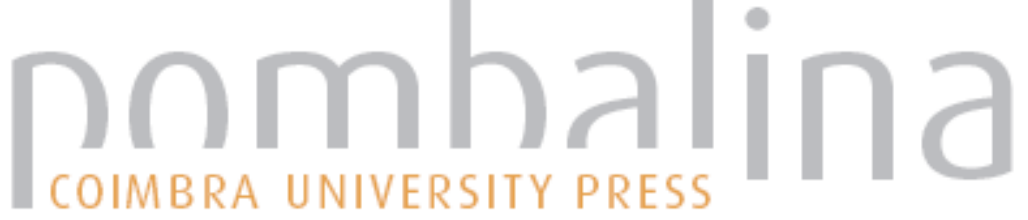

\section{Construcción de escenarios sociales de riesgo por fenómenos volcánicos en Colombia}
Autor(es):
Hernández Peña, Yolanda; Vargas Cuervo, Germán
Publicado por: Imprensa da Universidade de Coimbra; RISCOS - Associação
URL persistente:
Portuguesa de Riscos, Prevenção e Segurança
DOI:
URI:http://hdl.handle.net/10316.2/34832
DOI:http://dx.doi.org/10.14195/978-989-96253-3-4_38
Accessed : $\quad$ 26-Apr-2023 01:37:40

A navegação consulta e descarregamento dos títulos inseridos nas Bibliotecas Digitais UC Digitalis, UC Pombalina e UC Impactum, pressupõem a aceitação plena e sem reservas dos Termos e Condições de Uso destas Bibliotecas Digitais, disponíveis em https://digitalis.uc.pt/pt-pt/termos.

Conforme exposto nos referidos Termos e Condições de Uso, o descarregamento de títulos de acesso restrito requer uma licença válida de autorização devendo o utilizador aceder ao(s) documento(s) a partir de um endereço de IP da instituição detentora da supramencionada licença.

Ao utilizador é apenas permitido o descarregamento para uso pessoal, pelo que o emprego do(s) título(s) descarregado(s) para outro fim, designadamente comercial, carece de autorização do respetivo autor ou editor da obra.

Na medida em que todas as obras da UC Digitalis se encontram protegidas pelo Código do Direito de Autor e Direitos Conexos e demais legislação aplicável, toda a cópia, parcial ou total, deste documento, nos casos em que é legalmente admitida, deverá conter ou fazer-se acompanhar por este aviso.

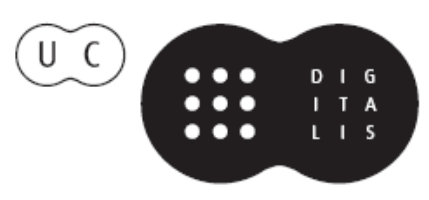



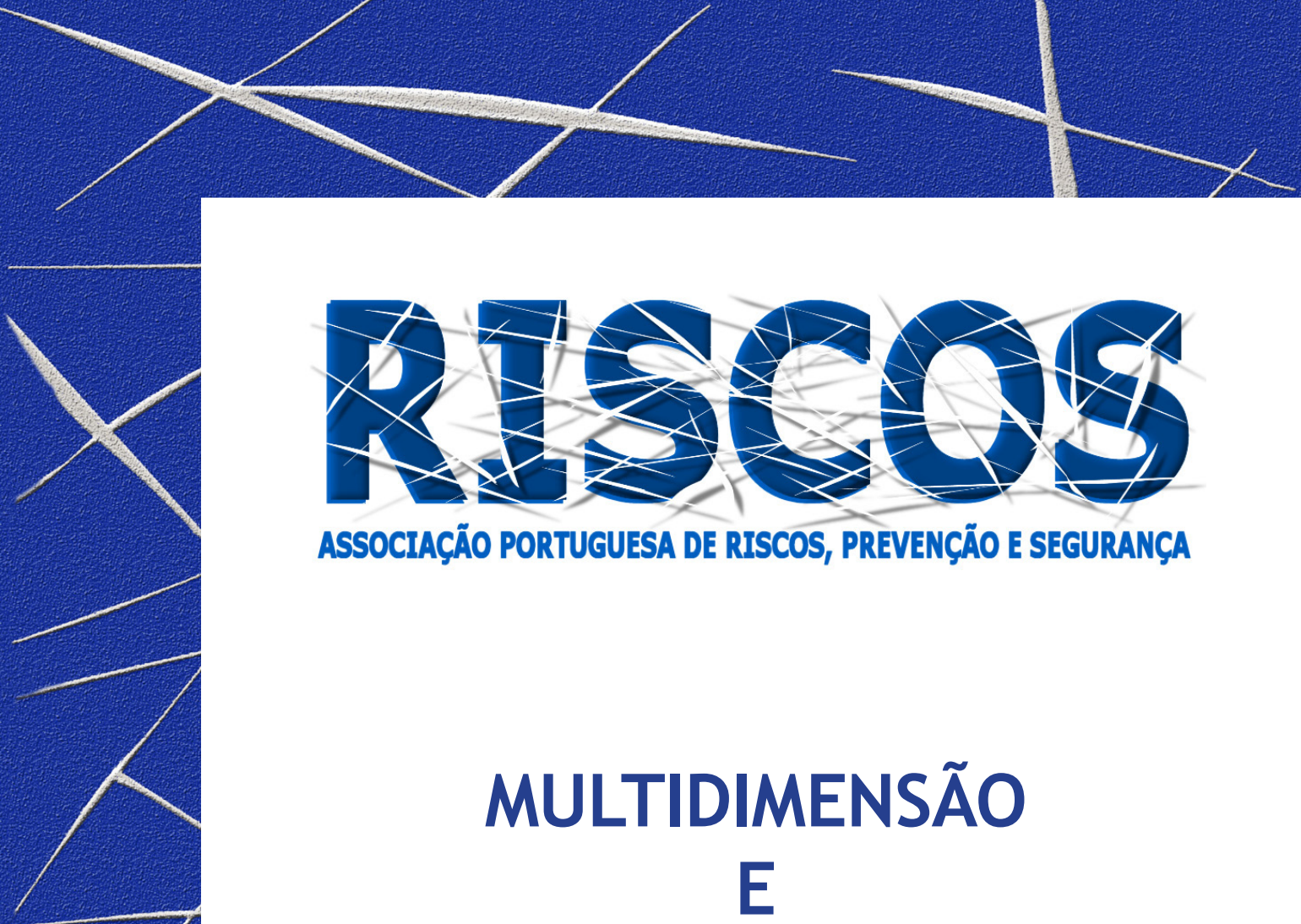

ASSOCIAÇÃO PORTUGUESA DE RISCOS, PREVENCCÃO E SEGURANÇA

MULTIDIMENSÃO

E
TERRITÓRIOS DE RISCO

III Congresso Internacional

I Simpósio Ibero-Americano

VIII Encontro Nacional de Riscos

Guimarães

2014 


\title{
CONSTRUCCIÓN DE ESCENARIOS SOCIALES DE RIESGO POR FENÓMENOS VOLCÁNICOS EN COLOMBIA
}

\author{
Yolanda Hernández Peña \\ Facultad del Medio Ambiente y Recursos Naturales, Universidad Distrital Francisco José de Caldas \\ ythernandezp@udistrital.edu.co \\ Germán Vargas Cuervo \\ Departamento de Geografía, Universidad Nacional de Colombia \\ gvargasc@unal.edu.co
}

\begin{abstract}
RESUMEN
Colombia se encuentra en el "Cinturón de fuego del Pacífico", por tanto, los volcanes existentes a lo largo de su territorio han desempeñado un importante papel en el desarrollo y evolución de su dinámica territorial, dado que importantes asentamientos se encuentran en áreas de influencia volcánica. El objetivo de esta ponencia es presentar los distintos procesos que han realizado las comunidades locales habitantes de zonas de influencia de fenómenos volcánicos como: El Galeras, El Machin, Del Huila y Del Ruiz y que han constituido escenarios diferenciales de riesgo, como también de procesos de adaptación y recuperación, los cuales se constituyen en factores de aprendizaje para las políticas y estrategias de gestión del riesgo. Para la investigación se utilizó una metodología mixta, de análisis basado en imágenes de satélite, y de enfoque etnográfico. Los hallazgos evidencian distintas construcciones culturales y procesos históricos alrededor de los fenómenos volcánicos, lo cual se constituye en importantes elementos para la gestión del riesgo.

Palabras clave: Volcanes, Colombia, Resiliencia, Gestión, Riesgo
\end{abstract}

\section{Introducción}

Los escenarios de riesgo se construyen a partir la presencia de factores de orden histórico y sociocultural, que en ocasiones pueden aumentar la vulnerabilidad de las poblaciones, o también explican las razones no convencionales, para la presencia de comunidades en zonas de influencia volcánica. Los escenarios sociales de riesgo presentados son el resultado de una investigación doctoral en geografía, de la Universidad Nacional de Colombia; acerca de imaginarios y percepciones de las poblaciones sobre los fenómenos amenazantes, en este caso los volcanes. Para realizar la investigación se acudió a un enfoque etnográfico. El trabajo de campo se realizó durante los años 2010 y 2011, con informantes clave, representantes de comunidades indígenas y campesinas. El objetivo de la ponencia es dar a conocer esos factores de orden social, cultural e histórico que inciden en la construcción de escenarios de riesgo. Como resultado se evidencia que no para todas las comunidades el fenómeno volcánico es amenazantes y que esto incide en el éxito de las estrategias de gestión del riesgo; igualmente se encuentra que los factores culturales se entrecruzan con elementos de carácter histórico, como despojo de tierras y desplazamiento, lo cual es un factor explicativo de la presencia de comunidades en zonas volcánicas.

\section{Los escenarios de riesgo volcánico en Colombia}

En Colombia, Estudios del Banco Mundial señalan que los eventos generados por las erupciones volcánicas y los sismos generan los índices más altos de pérdidas en viviendas destruidas y de vidas, para el periodo de 1970-2011 las muertes por erupciones llegaron a 24.456 muertos (Campos, Holm-Nielsen, \& Diaz, 2012), en concordancia con esto, al realizar una revisión sobre los estudios vinculados con zonas de amenaza volcánica y vulnerabilidad de las poblaciones, se encuentra que aproximadamente 1,9 millones de personas asentadas en zonas de influencia de 
estos fenómenos, y de estos 240 se encuentran en la zona de amenaza alta (OSSO, 2011). En la siguiente Tabla 1 se presenta una síntesis de las principales características de los escenarios de riesgo volcánico analizados.

Tabla 1 Descripción general del fenómeno volcánico y factores asociados

\begin{tabular}{|c|c|c|}
\hline Fenómeno volcánico & Condiciones territoriales & $\begin{array}{l}\text { Actores sociales asentados en la zona } \\
\text { de influencia }\end{array}$ \\
\hline $\begin{array}{l}\text { Volcán Nevado del Huila: La altura del } \\
\text { Pico Central es de } 5364 \text { m, corresponde al } \\
\text { punto más alto de la cordillera Central y } \\
\text { de los Andes en Colombia. Cuenta con un } \\
\text { casquete glaciar, que según (Ingeominas, } \\
\text { 2000) es drenado por el río Páez, con } \\
\text { una red de drenaje radial excéntrica en } \\
\text { el edificio volcánico, corriendo por un } \\
\text { cañón estrecho hasta el río Magdalena. }\end{array}$ & $\begin{array}{l}\text { Es una amenaza latente para los } \\
\text { habitantes del municipio de Páez, } \\
\text { población ubicada en los límites entre } \\
\text { los departamentos de Cauca y Huila, } \\
\text { en el suroeste de Colombia. El nivel de } \\
\text { alerta en la región es amarillo, dado que } \\
\text { la actividad sísmica en la montaña es } \\
\text { constante (Prada, 2013) }\end{array}$ & $\begin{array}{l}\text { Con aproximadamente } 33 \text { mil habitantes } \\
\text { expuestos a amenaza alta (Campos, } \\
\text { Holm-Nielsen, \& Diaz, 2012). Paez } \\
\text { es el municipio ubicado en su zona } \\
\text { de influencia, con una población de } \\
40.643 \text { habitantes, de los cuales } 30.923 \\
\text { son indígenas Nasa, el resto de la } \\
\text { población es afrocolombiana y mestiza } \\
\text { (Dane,2005). Los Nasa cultivan el maíz y } \\
\text { utilizan una forma de cooperación para } \\
\text { el trabajo denominado minga. }\end{array}$ \\
\hline $\begin{array}{l}\text { Volcán Machín: Con } 2750 \mathrm{msnm} \text {, es el } \\
\text { volcán activo, con menor altura sobre el } \\
\text { nivel del mar y el único con menos de } \\
4000 \text { metros, tiene un edificio volcánico } \\
\text { de varios anillos piroclásticos de } 2.4 \mathrm{~km} \\
\text { de diámetro y alturas de menos } 100 \mathrm{~m} \\
\text { sobre el basamento (Calvache, 2002). }\end{array}$ & $\begin{array}{l}\text { Para (Ingeominas, 2002), la zona de } \\
\text { influencia del Volcán comprende parte } \\
\text { de los departamentos de Tolima, } \\
\text { Cundinamarca y Quindío, con centros } \\
\text { urbanos como lbagué, Armenia, Girardot, } \\
\text { y } 12 \text { municipios más. }\end{array}$ & $\begin{array}{l}\text { Existen } 31 \text { mil habitantes expuestos a } \\
\text { amenaza alta, (Campos, Holm-Nielsen, } \\
\text { \& Diaz, 2012). El } 35 \% \text { de la población } \\
\text { vive en la cabecera de Cajamarca y } \\
\text { el } 65 \% \text { en el resto, el } 99,5 \% \text { vive en } \\
\text { hogares particulares y el } 0,5 \% \text { vive en } \\
\text { alojamientos especiales (Vega, 2013). }\end{array}$ \\
\hline $\begin{array}{l}\text { Volcán Nevado del Ruíz: Posee una forma } \\
\text { alargada en dirección NE - SW, algo } \\
\text { achatado y con un diámetro mayor en } \\
\text { su base de } 15 \mathrm{~km} \text { de longitud, con un } \\
\text { cráter activo de } 870 \times 830 \text { m de diámetro } \\
\text { y profundidad de } 247 \mathrm{~m} \text {. (Ingeominas, } \\
\text { 2010). }\end{array}$ & $\begin{array}{l}\text { En su zona de influencia están los } \\
\text { municipios de Manizales, Villamaría, } \\
\text { Palestina, Chinchiná y Neira. } 85 \text { familias } \\
\text { habitan la zona de alta vulnerabilidad } \\
\text { (Giraldo, 2012). - }\end{array}$ & $\begin{array}{l}\text { Cuenta con } 26 \text { mil habitantes ubicados } \\
\text { en la zona de amenaza, (Campos, Holm- } \\
\text { Nielsen, \& Diaz, 2012) }\end{array}$ \\
\hline $\begin{array}{l}\text { Volcán Galeras: Ubicado al sur del país, } \\
\text { en el departamento de Nariño a } 512 \\
\mathrm{~km} \text { al suroeste de Bogotá. De acuerdo } \\
\text { a (Ingeominas, 2000) tiene una forma } \\
\text { cónica, la cima del edificio destruido } \\
\text { tiene una altura de } 4276 \mathrm{~m} \text {, su drenaje es } \\
\text { radial excéntrico. }\end{array}$ & $\begin{array}{l}\text { En la zona de influencia se encuentran } \\
\text { siete municipios entre ellos la } \\
\text { ciudad capital Pasto y una serie de } \\
\text { corregimientos y veredas que albergan } \\
\text { aproximadamente } 500.000 \text { habitantes }\end{array}$ & $\begin{array}{l}\text { Tiene } 10 \text { mil habitantes en su zona de } \\
\text { amenaza alta (Campos, Holm-Nielsen, } \\
\text { \& Diaz, 2012). Parte de la zona está } \\
\text { habitado por indígenas Quillasingas } \\
\text { y campesinos quienes se dedican a } \\
\text { la agricultura de trigo, maíz, ulloco, } \\
\text { arveja, cebada, hortalizas, ARD (2003). }\end{array}$ \\
\hline
\end{tabular}

\section{Construcción de escenarios sociales de riesgo}

En los escenarios sociales de riesgo convergen una serie de factores relacionados con los procesos históricos de apropiación del territorio, y características culturales relacionadas con el conocimiento del territorio y del fenómeno derivado de esta apropiación, las cosmologías asociadas al significado del fenómeno volcánico para la comunidad y las tradiciones correlacionadas con ese significado. Igualmente, en estos escenarios tienen lugar acciones para la gestión del riesgo, las cuales pueden generan incompatibilidades con los procesos locales o por el contrario tener resultados exitosos, dentro de las incompatibilidades se encuentran problemas de comunicación entre autoridades y poblaciones locales y desacuerdos sobre temas legales, administrativos y técnicos, muchas veces generados por distintas concepciones sobre el fenómeno mismo como se ve en la Tabla 2. 
Tabla 2 Factores sociales e históricos en la construcción de escenarios de riesgo

\begin{tabular}{|c|c|c|c|}
\hline Volcán & $\begin{array}{l}\text { Imaginarios y percepciones } \\
\text { sobre el fenómeno }\end{array}$ & Procesos históricos & \begin{tabular}{|llll}
$\begin{array}{l}\text { Escenarios de } \\
\text { riesgo }\end{array}$ & gestion del \\
\end{tabular} \\
\hline Nevado del Huila & $\begin{array}{l}\text { Para los indígenas } \\
\text { Volcán representa el el padre } \\
\text { preceptor, que a partir de } \\
\text { la avalancha de } 1994 \text { les } \\
\text { hizo reaccionar ante los } \\
\text { procesos de aculturación } \\
\text { que los estaban afectando y } \\
\text { recuperarse como etnia. }\end{array}$ & $\begin{array}{l}\text { Para las } \\
\text { entrevistadas existe una } \\
\text { memoria histórica de larga } \\
\text { duración, que les permite } \\
\text { reconocerse como pueblo } \\
\text { y considerar el fenómeno } \\
\text { como una manifestación de } \\
\text { la naturaleza en beneficio } \\
\text { de su pueblo, para ellos la } \\
\text { avalancha generada por el } \\
\text { deshielo del Volcán era el } \\
\text { presagio del nacimiento de un } \\
\text { héroe cultural. }\end{array}$ & $\begin{array}{l}\text { A partir de su cosmovisión, } \\
\text { ellos consideran que se } \\
\text { encuentran en zona de riesgo y } \\
\text { han logrado una convergencia } \\
\text { de conocimientos técnicos y } \\
\text { locales para la construcción } \\
\text { procesos de monitoreo y } \\
\text { alerta }\end{array}$ \\
\hline Machín & $\begin{array}{|lr|}\text { Se encuentra en una zona } \\
\text { estratégica, debido a la } \\
\text { cercanía a una zona de } \\
\text { riqueza aurífera, y porque } \\
\text { es un corredor obligado de } \\
\text { circulación del país. Para } \\
\text { parte de su población dejar } \\
\text { la zona de amenaza puede } \\
\text { significar perder sus valiosos } \\
\text { territorios por el interés de } \\
\text { algunos particulares. } \\
\end{array}$ & $\begin{array}{l}\text { No hay experiencias sobre } \\
\text { eventos ocurridos en la } \\
\text { zona, el conocimiento } \\
\text { sobre erupciones es el dado } \\
\text { por las investigaciones } \\
\text { vulcanológicas, por tanto } \\
\text { habitaban sobre el domo, } \\
\text { hasta los sismos ocurridos } \\
\text { en 1982, los cuales los } \\
\text { hicieron reaccionar sobre la } \\
\text { peligrosidad del volcán. }\end{array}$ & $\begin{array}{l}\text { Los campesinos han realizado } \\
\text { trabajos de concientización } \\
\text { sobre el riesgo, han hecho } \\
\text { videos sobre rutas de } \\
\text { evacuación y esto ha } \\
\text { visibilizado y generado mayor } \\
\text { conciencia sobre su situación. }\end{array}$ \\
\hline Nevado del Ruíz & $\begin{array}{l}\text { El volcán es un atractivo } \\
\text { turístico, ha traído riqueza a } \\
\text { los suelos y es un emblema del } \\
\text { territorio }\end{array}$ & $\begin{array}{l}\text { En este escenario de riesgo } \\
\text { se evidencia la pérdida de } \\
\text { memoria histórica hasta 1985, } \\
\text { no tenian conocimiento de } \\
\text { eventos anteriores. Mucha } \\
\text { gente ignoraba que fuera un } \\
\text { Volcán (Cardona, Wilches- } \\
\text { Chaux, García, \& Mansilla, } \\
\text { 2004) }\end{array}$ & $\begin{array}{l}\text { La ocurrencia de la avalancha } \\
\text { de } 1985 \text { marcó un hito. Surge } \\
\text { el Sistema Nacional para la } \\
\text { Prevención y Atención de } \\
\text { Desastres, es el desastre que } \\
\text { más víctimas humanas ha } \\
\text { producido en Colombia. }\end{array}$ \\
\hline Galeras & $\mid \begin{array}{lrrr}\text { La } & \text { estrategia de reubicación } \\
\text { de la población } & \text { generó } \\
\text { un } & \text { movimiento } & \text { de } \\
\text { reacción, a partir } & \text { de } & \text { la } \\
\text { cual ellos reivindicaron } & \text { el } \\
\text { reconocimiento de su estatus } \\
\text { indígena, lo cual implica } \\
\text { una relativa } \text { autonomía } \\
\text { en el manejo de asuntos } \\
\text { territoriales }\end{array}$ & $\begin{array}{l}\text { Las comunidades indígenas } \\
\text { en la época de colonia fueron } \\
\text { despojadas y reducidas a } \\
\text { resguardos, pero en 1940 } \\
\text { estos fueron diezmados de } 88 \\
\text { resguardos a } 19 \text { y se procedió } \\
\text { a su parcelación, todo ello } \\
\text { ha ocasionado problemas } \\
\text { de escasez de tierra, López } \\
\text { (2000). }\end{array}$ & $\begin{array}{l}\text { Desencuentros en la gestión, } \\
\text { las comunidades no se sienten } \\
\text { reconocidas frente a las } \\
\text { estrategias de reubicación. } \\
\text { Para los Quillasingas, el Volcán } \\
\text { no es una amenaza y por tanto } \\
\text { allí no hay riesgo. }\end{array}$ \\
\hline
\end{tabular}

\section{Conclusiones}

Los escenarios sociales de riesgo se construyen a partir de las diferentes concepciones y percepciones sobre el fenómeno volcánico, así para los quillasingas el Volcán Galeras no es una amenaza; para los indígenas Nasa el volcán del Huila es un importante elemento cultural, al constituirse en un preceptor sobre sus acciones cotidianas; para las comunidades asentadas en la zona del V. Machín y del V. Ruíz estos fenómenos si son amenazantes, para los primeros por los temblores de la década del 80 y para los segundos por lo ocurrido con la desaparición de Armero en 1985. Estas concepciones sobre el fenómeno natural inciden en la estrategia de gestión del riesgo, dado que en ocasiones puede ayudar a fortalecerla como ocurre con los Nasa o por el contrario obstaculizar acciones como reubicaciones temporales, o reasentamientos. Para las comunidades indígenas y campesinas es difícil pensar en cambios en sus asentamientos, por el temor a la pérdida del tejido social y a la relación establecida con el territorio. Para la gestión del riesgo, es importante repensar la experiencia de los Nasa e Ingeominas acerca de la 


\section{CAPÍTULO 3.1: RISCOS GEOLÓGICOS E GEOMORFOLÓGICOS}

construcción de conocimiento emergente y corresponsabilidad para monitorear el fenómeno, con la mediación del conocimiento técnico-científico y el de las poblaciones.

\section{Bibliografía}

Ard. (2003). Código Periferia Urbana. Pasto: UDENAR.

Calvache, M. (2002). Análisis integral de riesgo volcánico en Colombia. Cátedra Ambiental. 17 Conferencia (pág. 20). Quindio: Corporación Autónoma Regional del Quindio.

Campos, A., Holm-Nielsen, N., \& Diaz, C. (2012). Análisis de la gestión de riesgo de desastres en Colombia. Bogotá: Banco Mundial.

Cardona, O., Wilches-Chaux, G., García, X., \& Mansilla, E. (2004). Estudio sobre desastres ocurridos en Colombia: Estimación de pérdidas y cuantificación de costos. Bogotá: Banco Mundial, Agencia Colombiana de Cooperación Internacional, Planeación Nacional.

Giraldo, R. (11 de 03 de 2012). Vanguardia.com. Recuperado el 06 de 2014, de Continua la alerta naranja en el Volcán Nevado del Ruíz: http://www.vanguardia.com/actualidad/colombia/151881-continuaalerta-naranja-en-volcan-nevado-del-ruiz

Ingeominas. (2000). Servicio geológico colombiano. Recuperado el 30 de 10 de 2012, dehttp://seisan.ingeominas.gov.co/RSNC/index. php?option=com_jevents\&task=icalrepeat.d.etail\&evid=368\&ltemid= 0\&year=2010\&month=06\&day=06\&uid $=17$ e42b5308c8bd85c954f62d946ac9bf

Ingeominas. (2002). Evaluación de la Amenaza volcánica potencial del cerro Machín (Departamento del Tolima, Colombia). Memoria explicativa del mapa de amenaza. Manizales: Ministerio de Minas y Energía, Instituto de Investigación e Información Geocientífica Minero, ambiental y Nuclear, Subdirección de Amenazas Geoambientales.

Ingeominas. (2010). Instituto Colombiano de Geología y Minería. Recuperado el 4 de Diciembre de 2010, de http://www.ingeominas.gov.co/content/view/229/250/

OSSO, C. (2011). Comportamiento del riesgo en Colombia. Proyecto Análisis de la Gestión del Riesgo de Desastres en Colombia. Bogotá: Banco Mundial.

Prada, E. (24 de 05 de 2013). Agendapropia. com. Recuperado el 09 de 2014, de http://www.agendapropia. com/index.php/agenda-propia/informe-especial/1932-pobladores-de-las-faldas-del-volcan-nevadodel-huila-expertos-en-la-prevencion-del-riesgo

Vega, L. (2013). Evaluación integral del riesgo volcánico. Estudio de caso: El Cerro Machín Colombia. Bogotá: Universidad Nacional. 